\title{
Sistem Informasi Layanan Penjualan Aksesoris Handphone pada Toko Multiphone Berbasis Android
}

\author{
Anton Respati Pamungkas*1, Aryo Wicak Arkantoro ${ }^{2}$, Bintang Wijaya ${ }^{3}$ \\ ${ }^{1,3}$ Program Studi Sistem Informasi, STMIK AUB, Surakarta, Indonesia \\ ${ }^{2}$ Program Studi Sistem Komputer, STMIK AUB, Surakarta, Indonesia \\ e-mail: *1anton18@stmik-aub.ac.id, ${ }^{2}$ aryo.wicak@gmail.com, \\ 321671000856@student.stmik-aub.ac.id
}

\begin{abstract}
Abstrak
Multiphone adalah sebuah toko yang khususnya bergerak dalam bidang penjualan Aksesoris Handphone, semakin meningkatnya perkembangan toko Aksesoris Handphone sekarang ini telah menjadi toko penjualan yang sangat berkembang, mencatat lebih dari ribuan transaksi penjualan dalam setiap tahunnya sehingga menuntut pihak pemilik toko untuk dapat menyediakan layanan pemesanan bagi pelanggan guna menunjang transaksi penjualan dan pelayanan lebih baik. Metode pengembangan sistem yang digunakan dalam pengembangan sistem adalah metode watefall yang digunakan untuk menggambarkan model sistem adalah berupa flowchart, Unified Modelling Language (UML), Class Diagram, Activity Diagram dan Squence diagram serta dalam perancangan basis data menggunakan PhpMyadmin. Untuk mengimplementasikan sistem informasi penjualan dan pemesanan ini, dibutuhkan komponen pendukung agar dapat bekerja dengan baik. Komponen tersebut diantaranya menggunakan bahasa pemrograman PHP, Android dan Java, untuk penyimpanan data menggunakan database MySQL. Perancangan sistem ini diharapakan bisa membantu dan mengatasi permasalahan yang ada sehingga dapat bermanfaat bagi pihak-pihak yang berkepentingan. Dengan adanya Sistem Informasi tersebut dapat memudahkan toko Multiphone untuk melakukan promosi produk-produk yang di tawarkan dan mempermudah melakukan transaksi penjualan online sehingga dapat dilakukan kapan saja dan juga aman. Mempermudah pengolahan data dan pengolahan laporan.
\end{abstract}

Kata kunci-Sistem Informasi Layanan, Penjualan Aksesoris Handphone, Android, Android Studio

\begin{abstract}
Multiphone is a shop that is especially engaged in the sale of Mobile Accessories, the development of Mobile Accessories stores has now become a very developed sales shop, recording more than thousands of sales transactions every year so that it requires the shop owner to be able to provide ordering services for customers to use. support sales transactions and better service. The system development method used in system development is the waterfall method used to describe the system model in the form of flow diagrams, Unified Modeling Language (UML), Class Diagrams, Activity Diagrams, and squad diagrams and in database design using PhpMyadmin. To implement this sales and ordering information system, supporting components are needed in order to work properly. These components include the PHP, Android and Java programming languages, for data storage using the MySQL database. It is hoped that the design of this system can help and overcome existing problems so that it can be useful for the parties concerned. With the Information System, it can make it easier for Multiphone shops to promote products that offer and facilitate online sales transactions so that they can be done anytime and safely. Simplify data processing and report processing.
\end{abstract}

Received November 11, 2021; Revised November 25, 2021; Accepted December 17, 2021 
Keywords—Service Information Systems, Mobile Accessories Sales, Android, Android Studio

\section{PENDAHULUAN}

Perkembangan teknologi Informasi kini membuat hidup manusia yang serba cepat, simpel dan mudah. Teknologi memudahkan manusia untuk menunjang segala aktivitas kehidupan mulai dari urusan pekerjaan di kantor, rumah tangga, pelayanan publik bahkan pembelian barang secara online. Dengan adanya perkembangan tersebut sumber daya manusia dituntut harus mampu mengikuti dan menerapkan agar dapat mengelola suatu informasi dengan tepat, cepat dan akurat.

Sebuah perusahaan atau bidang bisnis baik kecil, menengah, maupun berskala besar, biasanya perlu menggunakan sebuah sistem informasi yang menunjang kegiatan perusahaan maupun usaha bisnis tersebut. Dengan adanya sistem informasi tersebut maka segala sesuatu kegiatan dapat terkontrol satu sama lain dengan baik.

Sistem penjualan pada umumnya digunakan oleh perusahaan atau toko untuk memberikan layanan penjualan pada pelanggannya, dimana dalam proses penjualan akan mempercepat proses pembelian pelanggan. Hal ini akan mengefisiensikan waktu yang digunakan untuk melayani pelanggan [3].

Pengunaan smartphone yang semakin meluas dan hampir digunakan untuk seluruh kalangan, menjadikan smartphone sebagai salah satu kebutuhan pokok. hal ini sehingga menjadikan peluang bisnis yang sangat menjanjikan. tidak mengherankan apabila saat ini banyak toko yang menjual aksesoris handphone yang mana untuk menjadikan handhpone kita menjadi lebih berbeda secara visual untuk memenuhi kebutuhan masyarakat yang menggunakan smartphone. Selain itu banyak pengguna smartphone belum mengetahui bagaimana cara perawatan smartphone yang baik dan benar, serta bagaimana menggunakan smartphone yang sehat. Hal tersebut antara lain disebabkan belum adanya suatu aplikasi yang dapat memenuhi kebutuhan pelanggan tersebut. Pelanggan tidak saja membutuhkan data sebagai bagian dari operasional pelangganan namun juga perlu pengetahuan bagaimana melakukan perawatan smarphone tersebut.

Toko Multiphone adalah sebuah usaha penjualan aksesoris, dan service handphone. Dalam proses penjualan pada toko Multiphone masih menggunakan sistem manual yaitu pelanggan harus datang langsung kelokasi untuk menanyakan informasi harga barang yang dijual dan biaya service handphone, lalu pelanggan akan membeli jika stock barang yang dibutuhkan pelanggan tersedia, dengan menggunakan sistem manual ini membuat pelanggan kesulitan dalam melakukan pembelian barang karena harus datang langsung ke toko karena tidak mengetahui barang yang dibeli ada stocknya apa tidak. Sedangkan pemilik toko juga harus menghafal ketersediaan stock barang yang dijual ditoko karena belum memiliki database yang ada didalam sebuah aplikasi komputer yang membuat pemilik toko kesulitan untuk menghitung laba dan keuntungan penjualan dikarenakan belum ada Sistem yang membantu untuk membuat laporan pendapatan harian, mingguan dan bulanan.

Berdasarkan uraian pada paragraph sebelumnya maka dibutuhkan suatu sistem informasi penjualan barang yang terkomputerisasi dan berbasis mobile android. Dengan begitu pelanggan dapat mengecek stock barang yang dibutuhkan melalui perangkat mobile android mereka. Hal ini juga memudahkan pihak pemilik toko untuk melayani pelanggan secara online dan memberikan informasi barang yang dijual kepada pelanggan secara online dan dapat membantu untuk membuat laporan pendapatan harian, mingguan dan bulanan.

\section{METODE PENELITIAN}

\subsection{Analisis Sistem}

Dalam kelemahan sistem, penulis menggunakan analisis PIECES yang terdiri dari performance, information, control, efficiency dan service [5]. Sebagai alat ukur untuk 
menganalisa kelemahan sistem diperlukan langkah untuk mengidentifikasi dan memberikan solusi terhadap kelemahan sistem yang ada, seperti Tabel 1 berikut:

Tabel 1. Analisis Pieces

\begin{tabular}{|c|c|c|}
\hline Analisis & Kelemahan Sistem & Solusi \\
\hline Performance & $\begin{array}{l}\text { Pengolahan data masih dilakukan } \\
\text { secara manual yaitu pelanggan harus } \\
\text { dating ke toko }\end{array}$ & $\begin{array}{l}\text { Bentuk formulir pendaftaran } \\
\text { berupa form, yang dapat } \\
\text { diinput melalui Android. }\end{array}$ \\
\hline Information & $\begin{array}{l}\text { Kebutuhan Informasi tentang stock } \\
\text { barang masih sulit, karena pelanggan } \\
\text { harus dating ketoko untuk bertanya }\end{array}$ & $\begin{array}{l}\text { Informasi yang ditampilkan } \\
\text { dapat dilihat melalui Android } \\
\text { tanpa datang ketoko }\end{array}$ \\
\hline Economy & $\begin{array}{l}\text { Secara tidak langsung pemilik toko } \\
\text { mengeluarkan banyak nota kertas } \\
\text { sehingga terjadi pemborosan }\end{array}$ & $\begin{array}{l}\text { Biaya dikeluarkan lebih hemat, } \\
\text { karna tidak perlu mengluarkan } \\
\text { banyak nota kertas }\end{array}$ \\
\hline Control & $\begin{array}{l}\text { Keamanan kurang karena seluruh } \\
\text { informasi stock barang masih } \\
\text { menggunakan belum melalui } \\
\text { komputterisasi, sehingga mudah } \\
\text { rusak atau sobek }\end{array}$ & $\begin{array}{l}\text { Sistem admin berbasis web jika } \\
\text { stock barang hilang masih ada } \\
\text { backup. }\end{array}$ \\
\hline Efficiency & $\begin{array}{l}\text { Proses yang masih manual } \\
\text { memerlukan banyak waktu, sehingga } \\
\text { pelanggan harus dating ketoko dan } \\
\text { menanyakan ketersdiaan barang }\end{array}$ & $\begin{array}{l}\text { Sistem berbasis Android lebih } \\
\text { efisien karna pelanggan dapat } \\
\text { menanyakannya melalui online }\end{array}$ \\
\hline Service & $\begin{array}{l}\text { Pemilik harus menghafal ketersdiaan } \\
\text { barang dan mencarinya di buku stock } \\
\text { barang }\end{array}$ & $\begin{array}{l}\text { Pemilik dan pelanggan bisa } \\
\text { melihat stock barang langsung } \\
\text { melalui aplikasi android }\end{array}$ \\
\hline
\end{tabular}

\subsection{Use Case Diagram}

Usecase diagram mendiskripsikan sebuah interaksi antar satu atau lebih aktor dengan sistem yang akan dibuat. Usecase diagram mendefinisikan fitur dari sistem atau apa yang bisa dilakukan oleh sistem seperti pada Gambar 2 berikut.

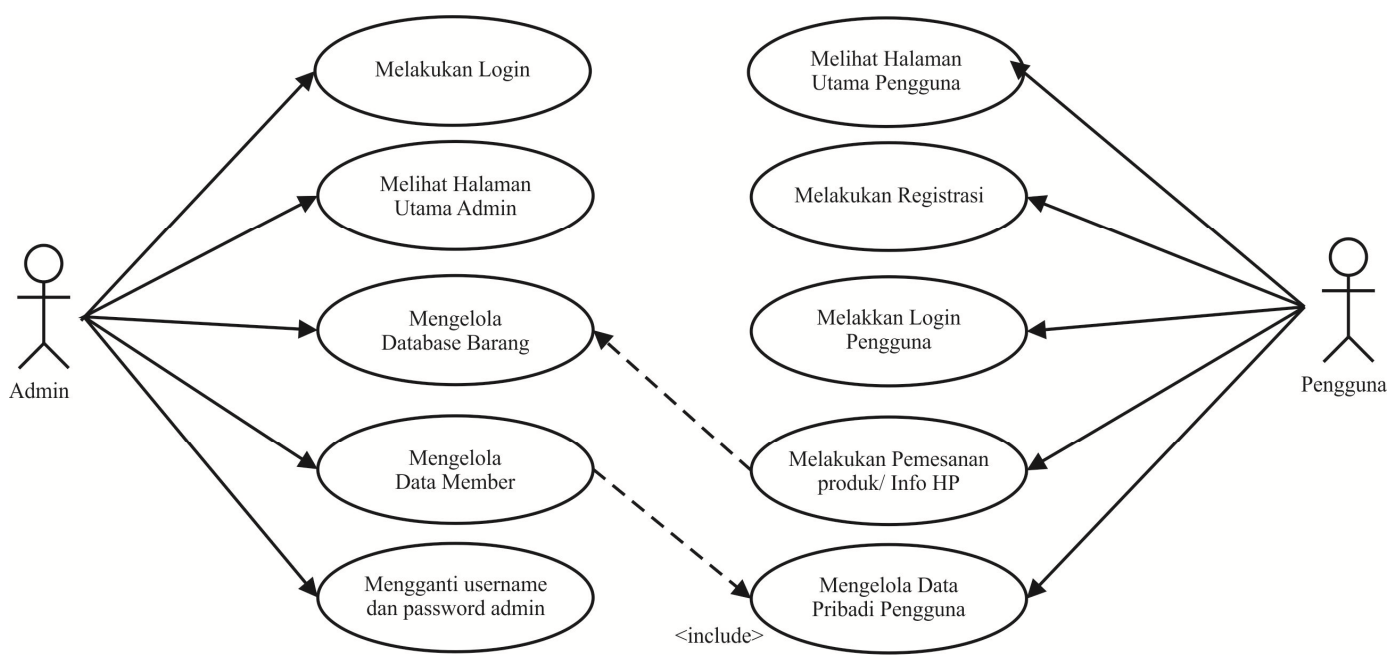

Gambar 2. UseCase Diagram 


\section{HASIL DAN PEMBAHASAN}

\subsection{Implementasi}

Dalam pembuatan aplikasi ini dibutuhkan suatu implementasi untuk menguraikan program dan analisis dari hasil program yang telah dibuat. Tujuan pembahasan ini adalah untuk mengetahui apakah program yang dibuat sudah bekerja seperti yang diharapkan atau belum. Berikut Gambar 3 hingga 10 adalah proses pembahasan interface atau antarmuka program:

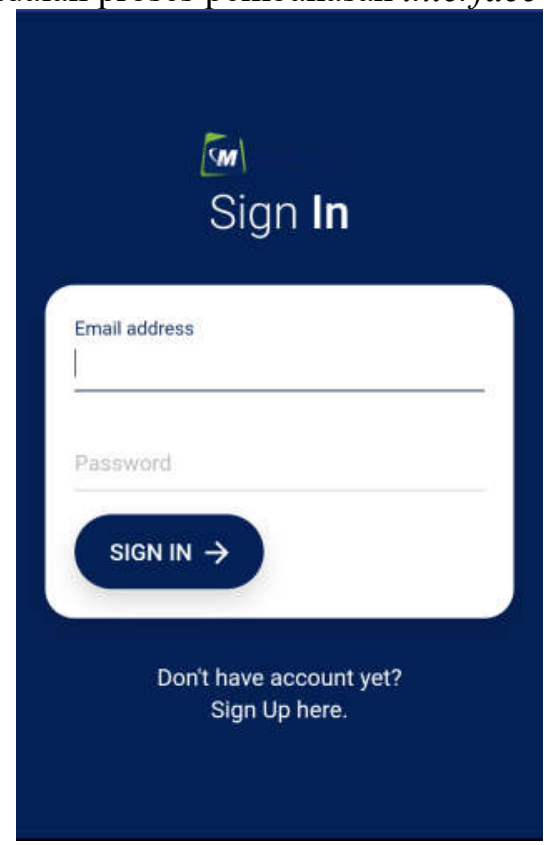

Gambar 3. Halaman Login admin

Halaman login admin digunakan oleh admin untuk masuk kedalam halaman admin. Admin harus memasukkan username dan password yang sudah terdaftar. Klik "Masuk" untuk masuk ke halaman utama admin.

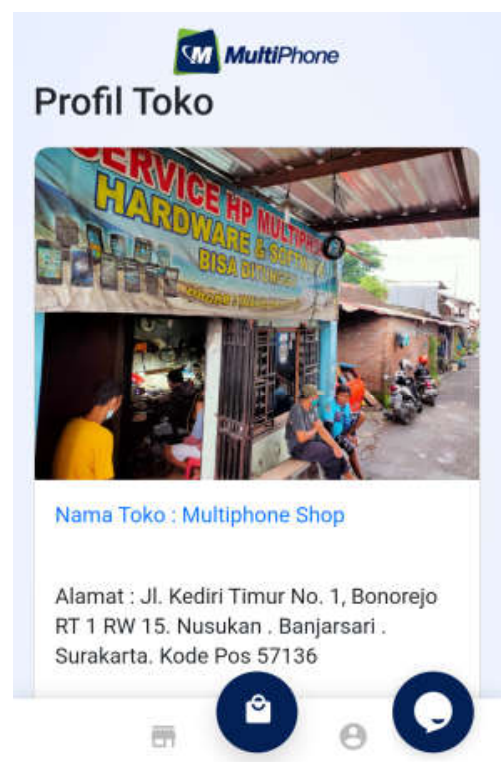

Gambar 4. Halaman Dashboard 


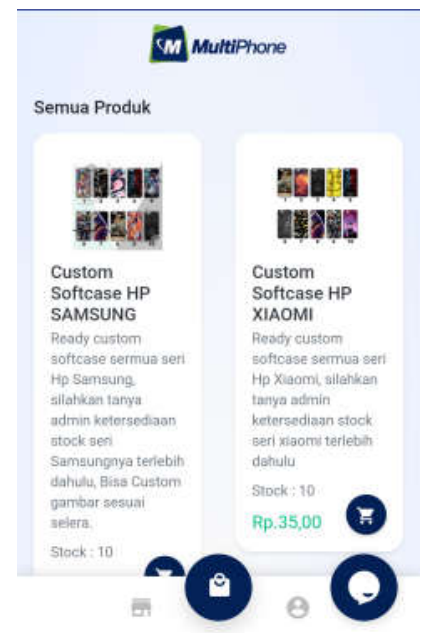

Gambar 5. Halaman Produk

Halaman produk akan menampilkan semua produk yang ada termasuk didalamnya. Gambar 5 halaman ini pengguna dapat melihat produk yang dijual, termasuk harga dan foto produk.

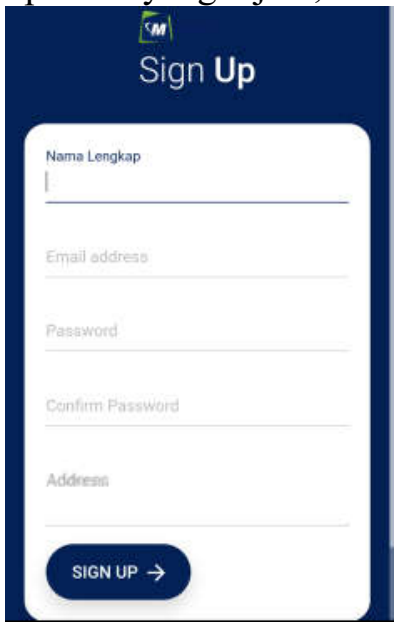

Gambar 6. Halaman Pendaftaran Konsumen Baru

Halaman ini dipergunakan bagi konsumen baru yang belum memiliki id dan user name, yang dipergunakan untuk melakukan login kedalam aplikasi. Kolom-kolom yang ada pada halaman ini harus diisi dengan lengkap agar anggota dapat melakukan pemesanan. 


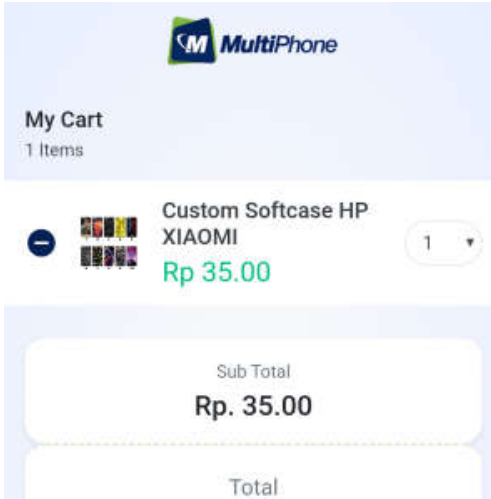

Rp. 35.00

CHECKOUT $\rightarrow$

파

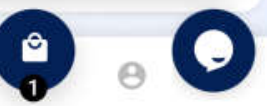

Gambar 7. Halaman Keranjang Belanja

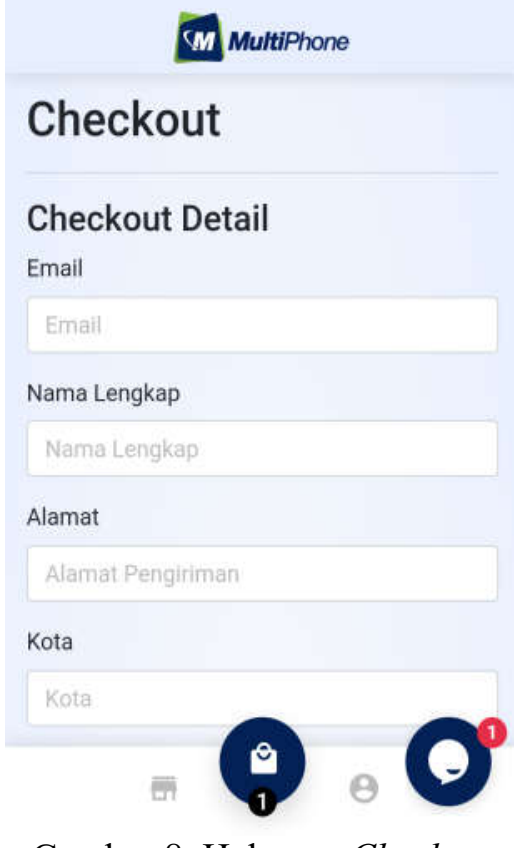

Gambar 8. Halaman Checkout 


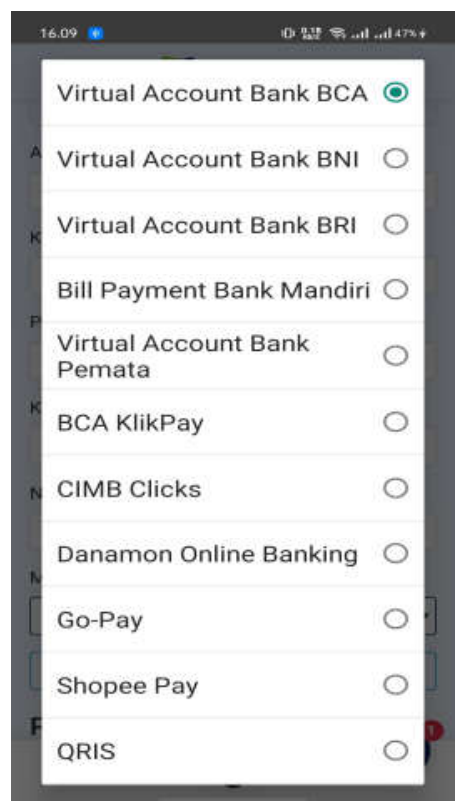

Gambar 9. Halaman Pemilihan Sistem Pembayaran

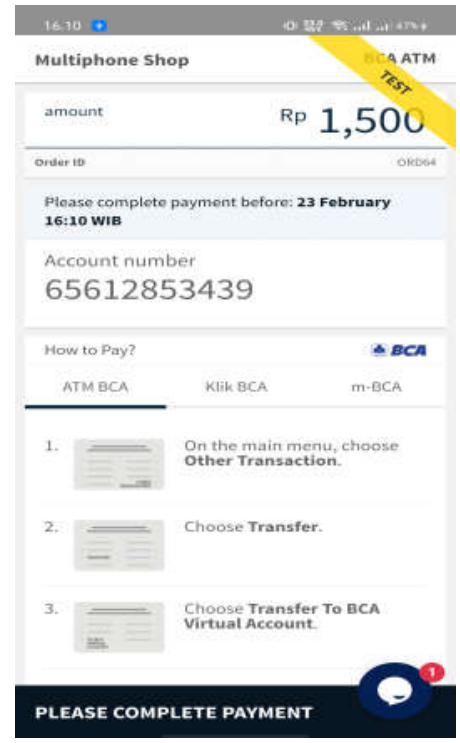

Gambar 10. Halaman Pemilihan Sistem Pembayaran Dengan Transfer

Halaman ini akan memproses pembayaran yang dilakukan oleh pembeli, termasuk didalamnya adalah cara pembayaran yang dapat dipilih oleh pembeli.

\section{KESIMPULAN}

Berdasarkan penelitian yang telah dilakukan, dapat diambil kesimpulan sebagai berikut sistem informasi layanan penjualan aksesoris handphone pada toko multiphone berbasis android disusun menggunakan analisa PIECES untuk mengoreksi dan memperbaiki sistem lama yang sedang berjalan dalam hal ini tertundanya pemrosesan pesanan karena antrian dari pesanan yang sebelumnya dan kurangnya informasi ditampilkan kepada calon pelanggan menjadi titik utama penelitian. Dalam hal pembangunan sistem dirancang dan digambarkan menggunakan flowchart, Unified Modelling Language, use case diagram, class diagram activity diagram dan squence diagram. Metode pengembangan sistem yang peneliti gunakan adalah metode waterfall. Sistem informasi layanan penjualan aksesoris handphone pada toko multiphone berbasis android dikembangkan dengan sistem admin berbasis web yang dibuat menggunakan bahasa pemrograman PHP, HTML dan Code Igniter. Pengembangan platform android menggunakan 
software android studio 4.0 dengan bantuan Ionic framework sebagai SDK front-end dan Apache cordova sebagai aplikasi pembungkus HTML / Javascript yang kemudian difungsikan dan diekspos melalui API sedangkan untuk database menggunakan PhpMyadmin yang kemudian semuanya diupload dalam hosting agar dapat digunakan secara online. Berdasarkan implementasi sistem informasi layanan penjualan aksesoris handphone pada toko multiphone berbasis android peneliti menyimpulkan bahwa telah berhasil membangun sistem informasi yang lebih baik untuk memudahkan pelanggan dalam pencarian informasi dan memudahkan admin dalam proses penjualan hingga pembuatan laporan penjualan.

\section{SARAN}

Sistem Informasi layanan penjualan aksesoris handphone pada toko multiphone berbasis android masih dapat dikembangkan oleh peneliti berikutnya lebih lanjut antara lain menambahkan notifikasi order via whatsapp sehingga admin dapat melihat dengan mudah adanya orderan masuk dan pelanggan dapat dengan mudah mengetahui produk yang dibeli sudah diproses pengiriman. Pemesanan produk sebaiknya dapat menggunakan metode preorder.

\section{DAFTAR PUSTAKA}

[1] Febri Nugroho. 2016. Sistem Penjualan Pada Perangkat Bergerak Berbasis Android Menggunakan Web Service. Skripsi. Program Studi Teknik Informatika. Jurusan Teknik Informatika. Fakultas Sains Dan Teknologi. Universitas Sanata Dharma Yogyakarta

[2] Imamul Huda. 2011, Pengembangan Aplikasi P3k Berbasis Smartphone Android. Skripsi. Program studi teknik informatika . Fakultas sains dan teknologi. Universitas islam negeri syarif hidayatullah. Jakarta

[3] Ivan Alfatih Saputra. 2017. Aplikasi Layanan Bengkel Mobil Berbasis Android Di Kota Bandar Lampung. Skripsi. Jurusan Ilmu Komputer. Fakultas Matematika Dan Ilmu Pengetahuan Alam. Universitas lampung.

[4] Kanedi, I., dkk. 2013. Media Sarana Promosi Makanan Khas Bengkulu Berbasis Website Menggunakan Script PHP. Jurnal Media Infotama. Vol.9, No.2. 206225.

[5] Ragil, Wukil. 2017. Analisis menggunakan Metode Pieces. Jakarta: Metadata.

[6] Safaat H, Nazarudin. 2017. Pemograman Aplikasi Mobile Smartphone dan Tablet PC Berbasis Android. Bandung: Informatika.

[7] Zheing, Pei dan Ni, Lionel. 2016. Smartphone \& Next Generation Mobile Computing. Morgan Kaufman: San Fransisco. 